\title{
ANALISIS PENGARUH KUALITAS PELAYANAN TERHADAP KEPUASAN PELANGGAN BPU (Studi Kasus BPJS Ketenagakerjaan Magelang)
}

\author{
Anggita Windi ${ }^{1}$, Hanung Eka Atmaja ${ }^{2}$ \\ ${ }^{1}$ Jurusan Manajemen Fakultas Ekonomi Universitas Tidar Magelang, Indonesia \\ ${ }^{2}$ Jurusan Manajemen Fakultas Ekonomi Universitas Tidar Magelang, Indonesia \\ ${ }^{1}$ Email korespondensi: anggitawindi@gmail.com
}

\begin{abstract}
Service quality is the key to service providers to attract the hearts of customers. Service providers must provide facilities so that customer satisfaction can be fulfilled. Service providers can use several indicators such as Responsives, Tangibile, Assurance, Reliability, Emphaty. These indicators are used as benchmarks and assessments in providing services. With these indicators it will make it easier for service providers to provide the best service. These indicators are used as guidelines for service providers as a measurement of evaluation in assessments and the results of services. The method used in this research is quantitative, the measurement scale uses the Likert scale. A sample of 100 people with purposive sampling technique and data obtained by distributing questionnaires to respondents. The results showed that the results of the t-test test variables tangible, assurance, responsiveness, and empathy did not have a significant effect on the satisfaction of non-wage earners. Reliability has a significant impact on customer satisfaction.
\end{abstract}

Keywords: responsives, tangibile, assurance, reliability, emphaty

\begin{abstract}
ABSTRAK
Kualitas pelayanan merupakan suatu kunci perusahaan penyedia jasa untuk dapat menarik hati para pelanggan. Kualitas pelayanan yang diselenggarakan dengan baik akan memberikan Citra positif sehingga dapat menciptakan kepuasan pelanggan. Dalam penilaian kualitas pelayanan perusahaan penyedia jasa dapat menggunakan beberapa indikator seperti Responsives, tujuan dari penelitian ini adalah untuk mengetahui apak kualitas pelayanan berpengaruh terhadap kepuasan pelanggan dengan responsives, Tangibile, Assurance, Reliability, Emphaty. dijadikan sebagai tolok ukur. Dengan indikator tersebut akan mempermudah pemberi pelayanan untuk memberikan pelayanan terbaik. Indikator tersebut dijadikan pedoman bagi pemberi pelayanan sekaligus sebagai pengukuran konsumen dalam menilai proses serta hasil dari pelayanan. Metode yang digunakan dalam penelitian ini adalah kuantitatif, skala pengukuran menggunakan skala likert. Sampel sebanyak 100 orang dengan teknik purposive sampling dan data diperoleh dengan menyebar kuesioner kepada resoonden. Hasil penelitian menunjukkan bahwa hasil pengujian hipotesis uji t variabel tangibel, assurance, responsive, dan emphaty tidak berpengaruh signigifikan terhadap kepuasan pelanggan bukan penerima upah. Reliability berpengaruh signifikan terhadap kepuasan pelanggan.
\end{abstract}

Kata-Kata Kunci: responsives,tangibile, assurance, reliability, emphaty. 


\section{PENDAHULUAN}

Pada kondisi persaingan bisnis sekarang ini memperlihatkan bahwa bisnis harus terus berkembang dan dapat bersaing secara kompetitif. Perusahaan harus dapat menciptakan keunggulan agar dapat memperoleh pelanggan dan menjaga eksistensi perusahaan di mata publik. Pelaku bisnis harus bisa merebut pangsa pasar dan mengubah pandangan bahwa bisnis hanya berorientasi pada keuntungan semata tetapi harus menjadi sebuah keuntungan yang potensial salah satunya adalah memperoleh kepuasan pelanggan dengan cara memberikan pelayanan yang baik kepada pelanggan sehingga pelanggan dapat merasa terpuaskan dan akan menimbulkan loyalitas dalam diri konsumen terhadap produk yang dihasilkan. Perusahaan harus selalu melakukan perbaikan pelayanan serta menganggapi complain dari konsumen sehingga dapat mengikat loyalitas konsumen (Ellu, 2005).

Salah satu perusahaan yang berkembang dengan cepat di antaranya adalah industri jaminan kesejahteraan masyarakat atau yang biasa disebut dengan Asuransi. Dalam perusahaan jasa hal yang paling utama yang harus diperhatikan merupakan pelayanan. Kualitas pelayanan menjadi kunci utama untuk dapat merebut pangsa pasar dibandingkan dengan perusahaan lain. Ketika industri jasa dapat memberikan kualitas pelayanan yang memadai dan dapat memberi kepuasan kepada konsumen perusahaan akan mendapat citra baik dari konsumen. Seperti yang dikatakan Luvio di dalam Misrul Irawati (2008) bahwa perusahaan yang bergerak dalam bidang jasa harus memperlihatkan Citra karena dengan Citra yang baik maka dapat memberi nilai tambah bagi perusahaan dan juga membuat para konsumen senang dan betah bila kondisi di tempat perusahaan memberikan suasana yang nyaman,dan aman.Industri asuransi Harus Memiliki keunggulan serta karakteristik-karakteristik lainnya dalam memperoleh pelanggan. Banyaknya perusahaan pesaing yang mempunyai produk-produk yang sama maka perusahaan harus mempunyai kualitas yang berbeda dari perusahaan-perusahaan yang lain salah satunya adalah dengan meningkatkan kualitas pelayanan. Hal ini berguna karena pada saat ini konsumen akan semakin selektif dalam memilih jasa yang akan mereka gunakan, para konsumen akan berpikir untuk keuntungan di masa mendatang. Seperti yang dikatakan oleh Rohaeni (2016) bahwa pada saat ini kompetisi dalam dunia bisnis sangat terasa sehinnga perusahaan harus melakukan restrukturisasi. Maka dari itu perusahaan harus selalu melakukan pembaruan termasuk pada tingkat kualitas pelayanan sehingga dapat menghasilkan kepuasan bagi konsumen.

BPJS Ketenagakerjaan merupakan salah satu perusahaan asuransi yang memahami bahwa peranan pelanggan dalam bisnis mereka akan sangat berpengaruh. 
BPJS Ketenagakerjaan menyelenggarakan 4 program yaitu program jaminan kecelakaan kerja jaminan hari tua, jaminan kematian dan jaminan pensiun. Berdasarkan UU Nomor 24 Tahun 2011 pelayanan BPJS Ketenagakerjaan harus melindungi tenaga kerja di Indonesia yang meliputi tenaga kerja formal, tenaga kerja diluar hubungan kerja yang bekerja Mandiri pada usaha-usaha ekonomi informal, tenaga kerja harian lepas, tenaga kerja borongan dan perjanjian kerja waktu tertentu atau PKWT. Maka dari itu hal ini menjadi keuntungan sekaligus tantangan bagi BPJS Ketenagakerjaan untuk dapat merangkul seluruh tenaga kerja di Indonesia.

BPJS Ketenagakerjaan selalu melakukan evaluasi dan melakukan transformasi serta merubah strategi agar dapat merebut hati para pelanggan sehingga para pelanggan dapat percaya terhadap jasa yang mereka hasilkan. BPJS Ketenagakerjaan harus selalu berusaha untuk memberikan pelayanan yang terbaik sehingga konsumen merasa puas dan timbul kesan positif dalam benak konsumen yang membuat konsumen menjadi percaya serta yakin akan pilihannya memilih perusahaan asuransi ini. Kepercayaan dan keyakinan Konsumen akan memberikan dampak yang positif bagi pertumbuhan perusahaan.

Kualitas pelayanan merupakan keunggulan produk maupun jasa yang disediakan oleh perusahaan untuk memenuhi keinginan konsumen (Tjiptono, 2011). Dalam melakukan pengukuran kualitas pelayanan perusahaan dapat menggunakan indicator tangibles, reliability, responsives, assurance, dan emphaty ( Tjiptono, 2012:26). Cronin dan Taylor dalam Taslim Bahar (2009) mengatakan bahwa kepuasan konsumen merupakan faktor utama untuk menilai kualitas pelayanan di mana Konsumen akan menilai kinerja pelayanan yang diterima dan dirasakan terhadap produk suatu layanan. ketika konsumen merasakan kualitas pelayanan itu tinggi maka semakin tinggi pula tingkat kepuasan konsumen dan akan berdampak pada perilaku konsumen secara langsung. Peningkatan kualitas pelayanan yang dilakukan oleh BPJS Ketenagakerjaan diharapkan mampu membentuk kepuasan pelanggan dan dapat melebihi harapan dari pelanggan sehingga akan berdampak kepada perusahaan dan meningkatnya jumlah kepesertaan serta menumbuhkan kepercayaan masyarakat terhadap perusahaan hal ini dikarenakan kualitas meningkatkan rasa kepercayaan kepada perusahaan.

Penelitian ini merupakan pengembangan dari penelitian yang dilakukan oleh Arie Vica Septiarani (2013). Perbedaan penelitian ini terletak pada lokasi penelitian, perusahaan, pengukuran variable, dan teknik pengujian hipotesis. Teknik pengumpulan data dalam penlitian ini adalah purposive sampling dengan kuisioner dan dianalisis dengan menggunakan analisis regresi berganda dan pengujian hipotesis, sedangkan Arie 
Vica Septiarani (2013) mengukur tingkat kepuasan konsumen dengan menggunakan metode fuzzy servqual dan indeks PGCV. Dengan hasil bahwa konsumen belum merasa puas atas pelayanan yang diberikan oleh perusahaan.

Kepuasan konsumen menjadi factor penting dalam mencapai target perusahaan. Kepuasan konsumen juga akan menentukan keberlangsungan hidup perusahaan.Berdasarkan pengamatan yang dilakukan BPJS Ketenagakerjaan cabang Magelang belum sepenuhnya menerapkan aspek reliability, responsiveness, assurance, emphaty, dan tangibles. Hal ini menjadi daya Tarik penulis unuk meneliti tentang "Analisis Pengaruh Kualitas Pelayanan Terhadap Kepuasan Pelanggan BPU (Studi Kasus BPJS Ketenagakerjaan Magelang)".

Tujuan dari penelitian ini adalah untuk mengetahui (1). Apakah variable reliability berpengaruh terhadap kepuasan pelanggan. (2). Apakah variable responsives berpengaruh terhadap kepuasan pelanggan. (3). Apakah variable assurance berpengaruh terhadap kepuasan pelanggan. (4). Apakah variable tangible berpengaruh terhadap kepuasan pelanggan. (5). Apakah variable emphaty berpengaruh terhadap kepuasan pelanggan.

\section{METODE PENELITIAN}

Desain penelitian asosiatif kausal dengan pendekatan kuantitatif. Asosiatif kausal digunakan untuk mengetahui hubungan atau pengaruh dari dua variabel atau lebih. Penelitian ini menggunakan pendekatan kuantitatif karena data yang akan diolah berbentuk skala numerik atau angka (Kuncoro, 2009). Penelitian ini menganalisis pengaruh kualitas pelayanan terhadap kepuasan pelanggan.

Penelitian ini diukur menggunakan skala likert, dengan standar ukuran :

1. Sangat Tidak Setuju (STS)

2. Tidak Setuju (TS)

3. $\operatorname{Netral}(\mathrm{N})$

4. Setuju (S)

5. Sangat Setuju (SS)

Populasi adalah seluruh bagian yang akan diteliti, sedangkan sampel merupakan bagian yang di ambil dari populasi. Sampel sering di ambil untuk mewakili seluruh populasi karyawan. (Istijanto, 2006). Sampel adalah bagian kecil yang diambil dari populasi. Sampel dalam penelitian ini dengan menggunakan teknik Purposive Sampling. Metode pengambilan sampel menggunakan purposive sampling yaitu dengan kriteria 
tertentu (Donald R Cooper, 1995). Responden merupakan pelanggan bukan penerima upah. Dengan sampel sebanyak 100 Responden.

Data yang digunakan yaitu data primer. Metode pengumpulan data dengan menggunakan kuisioner. Kuesioner berisi pertanyaan secara tertulis yang kemudian akan dijawab oleh responden (Sugiyono, 2005). Untuk mengukur pendapat dan persepsi responden dalam menjawab pertanyaan peneliti menggunakan skala likert, dengan rentang skor 1-5. Skala likert adalah skala yang digunakan untuk mengukur sikap pendapat dan persepsi seseorang atau sekelompok orang tentang fenomena sosial (Sugiyono, 2005). Dalam skala likert variabel yang diukur dijabarkan berdasarkan definisi operasional nya masing-masing. Skor pertanyaan pada setiap jawaban.

Analisis data diukur dengan uji validitas dan reliabilitas. Uji validitas digunakan untuk mengukur valid tidaknya suatu kuesioner. Kuesioner dikatakan valid jika pertanyaan pada kuesioner mampu mengungkapkan sesuatu yang akan diukur oleh kuesioner tersebut (Ghozali, 2013:52). Uji validitas dengan metode corrected item total correlation. Metode ini untuk mencari $\mathrm{T}$ hitung untuk dibandingkan dengan nilai $\mathrm{R}$ tabel dimana $\mathrm{DF}=\mathrm{n}$ dengan tingkat signigikansi $5 \%$.

Uji Reliabilitas menunjukkan konsistensi dan stabilitas dari suatu skala pengukuran uji reliabilitas memusatkan perhatian pada masalah konsistensi dan ketepatan (Kuncoro, 2009). Sujarweni (2014) mengatakan bahwa kuesioner dikatakan reliabel jika nilai Cronbach Alpha > 0,6. uji asumsi klasik menurut Ghozali (2016) attas Jika nilai sign. $<0,05$ maka artinya variabel independen (Y) secara parsial berpengaruh terhadap variabel dependen (X). Sujarweni (2014) mengatakan bahwa nilai F hitung > F tabel. Uji analisis regresi berganda.

$\mathrm{Y}=\mathrm{a}+\mathrm{b} 1 \mathrm{x} 1+\mathrm{b} 2 \times 2+\mathrm{b} 3 \times 3+\mathrm{b} 4 \times 4+\mathrm{b} 5 \times 5+\mathrm{e}$

$\mathrm{Y}=$ Kualitas Pelayanan

$\mathrm{X} 1=$ Reliability

$\mathrm{X} 2=$ Responsives

$\mathrm{X} 3$ = Assurance

$\mathrm{X} 4$ = Tangibel

$\mathrm{X} 5=$ Emphaty

$\mathrm{e}=$ Residual.

\section{PEMBAHASAN}

Pada bab ini akan mendeskripsikan mengenai hasil penelitian, hasil didapat berdasarkan kuesioner yang telah disebarkan kepada 100 responden nasabah Bukan 
Penerima Upah BPJS Ketenagakerjaan cabang Magelang. Kemudian data akan diolah dan dianalisis. Data disajikan dalam bentuk table dan gambar.

\section{Uji Validitas}

Uji validitas memberi gambaran mengenai interpretasi yang diharapkan dengan hasil pengukuran dengan taraf signifikansi 5\%. Menurut (Ghozali, 2016) menyatakan bahwa suatu kuisioner dinyatakan valid apabila nilai $\mathrm{r}$ yang diperoleh dari hasil perhitungan $(\Gamma$ ) lebih besar dari pada nilai dengan taraf siginifikan 5\%. Dari total pernyataan sebanyak 25 item dengan variabel Tangibles, Assurance, Reliablity, Responsives, Emphaty untuk kepuasan Pelanggan (Y) semuanya dinyatakan valid.

\section{Uji Reliabilitas}

Reliabilitas memusatkan perhatian pada konsistensi dan ketepatan pada skala pengukuran (Kuncoro, 2009). Suatu kuesioner dikatakan reliabel apabila jawaban seseorang terhadap pertanyaan dapat konsisten dari waktu ke waktu titik uji reliabilitas dimaksudkan untuk mengetahui sejauh mana hasil pengukuran tetap konsisten apabila dilakukan pengujian ulang sehingga hasil yang diperoleh dapat signifikan. (Sujarweni,2014) menyatakan bahwa kuesioner dapat dikatakan reliabel jika nilai cronbach's alpha> 0.6 .

Tabel 1. Uji Reliabilitas

\begin{tabular}{ll}
\hline Reliability Statistics \\
\hline Cronbach's Alpha & N of Items \\
\hline .835 & 30 \\
\hline
\end{tabular}

Sumber: Data Peneliti, 2020.

Uji realibiltias menyatakan bahwa nilai Cronbach's Alpha sebesar $0.835>0,6$. Maka item diatas dinyatakan reliabel.

\section{Uji Normalitas}


Uji normalitas digunakan untuk menguji apakah data berdistribusi normal atau tidak. Menurut (Ghozali, 2016) menyatakan bahwa model regresi dikatakan berdistribusi normal jika data ploting yang menggambarkan data sesungguhnya mengikuti garis diagonal.

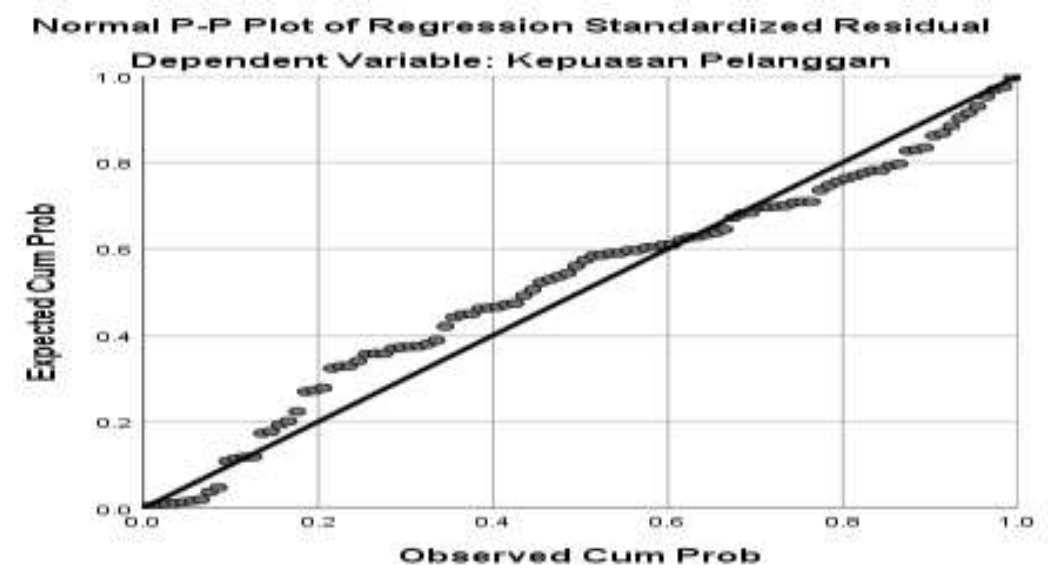

Gambar 1. Uji Normalitas

Sumber: Data Peneliti, 2020.

Data menunjukkan bahwa gambar berdistrbusi Normal karena titik-titiknya menggambarkan dan mengikuti garis diagonal.

\section{Uji Multikolinearitas}

Uji multikolinearitas merupakan uji yang dilakukan untuk mengetahui ada tidaknya kemiripan variabel independen yang kita pilih dengan variabel independen yang lain dalam satu model. Menurut Nugroho (2015) untuk menguji multikolinearitas terdapat dua hal yang harus diperhatikan yaitu nilai VIF tidak boleh lebih dari 10 dan nilai tolerance tidak boleh kurang dari 0,1. Jika pernyataan tersebut terpenuhi maka model dinyatakan bebas dari uji multikolinearitas. 
Tabel 2. Uji Multikolinearitas

\begin{tabular}{|c|c|c|c|c|c|c|c|}
\hline \multicolumn{8}{|l|}{ Coefficients $\mathrm{s}^{\mathrm{a}}$} \\
\hline \multirow{2}{*}{ Model } & \multicolumn{2}{|c|}{$\begin{array}{l}\text { Unstandardiz } \\
\text { ed } \\
\text { Coefficients }\end{array}$} & \multirow[t]{2}{*}{$\begin{array}{l}\text { Standa } \\
\text { rdized } \\
\text { Coeffi } \\
\text { cients } \\
\end{array}$} & \multirow{2}{*}{$\mathrm{T}$} & \multirow{2}{*}{ Sig. } & \multicolumn{2}{|c|}{$\begin{array}{l}\text { Collinearity } \\
\text { Statistics }\end{array}$} \\
\hline & & $\begin{array}{l}\text { Std. } \\
\text { Erro }\end{array}$ & & & & $\begin{array}{l}\text { Tol } \\
\text { eran }\end{array}$ & \\
\hline 1 (Constant) & .469 & $\begin{array}{l}1.33 \\
8\end{array}$ & & .351 & .727 & & \\
\hline Reliablity & .678 & .074 & .664 & 9.184 & .000 & .469 & 2.134 \\
\hline Responsives & .098 & .087 & .099 & 1.137 & .258 & .325 & 3.079 \\
\hline Assurance & .022 & .044 & .028 & .499 & .619 & .776 & 1.288 \\
\hline Emphaty & .111 & .081 & .125 & 1.366 & .175 & .291 & 3.440 \\
\hline Tangibles & .058 & .080 & .062 & .726 & .470 & .335 & 2.983 \\
\hline
\end{tabular}

Sumber: Data Peneliti, 2020.

Data menunjukkan bahwa nilai VIF dari masing-masing variabel tidak ada yang melebihi dari 10 dan nilai tolerance melebihi angka 0.1. Maka data dapat dikatakan bahwa model bebas dari uji multikolinearitas.

\section{Uji Heteroskedastisitas}

Menurut (Ghozali, 2016) tidak terjadi heteroskedastisitas, Jika tidak ada pola yang jelas (mengelombang, melebar kemudian menyempit) pada gambar scatterplot, serta titik- titik menyebar diatas dan dibawah angka 0 pada sumbu Y. sesuai dengan nilai distribusi nilai tabel maka dari hasil data dibawah.

Tidak ada pola yang jelas (bergelombang, melebar, kemudian menyempit), serta titik-titik menyebar diatas dan dibawah angka 0 pada sumbu Y. jadi tidak terjadi heteoskadistisitas karena tidak ada pola yang jelas (bergelombang, melebar, kemudian menyempit), serta titik-titik menyebar di atas dan di bawah angka 0 pada sumbu Y. 


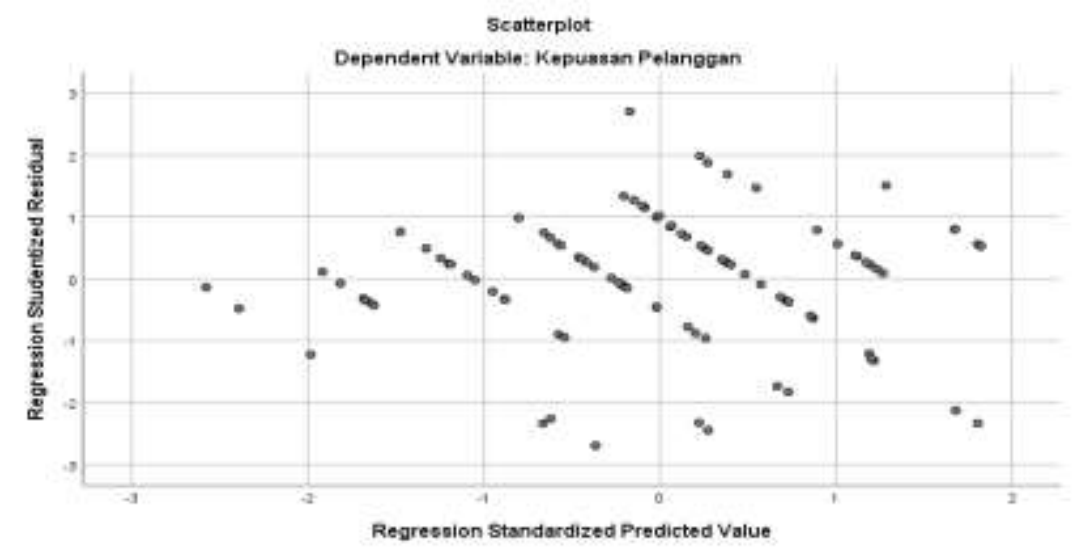

Gambar 2.

Uji Heteroskedastisitas

Sumber: Data Peneliti, 2020.

\section{Uji Autokorelasi}

Menurut Ghozali (2016) tidak ada gejala autokorelasi, jika nilai Durbin Watson terletak antara du sampai dengan (4-du). Hasil dibawah menyatakan Du (1.780) < Durbin Watson (2.112) 4-Du ( 2.220) menyatakan bahwa tidak ada gejala heteroskedstisitas. Berdasarkan pernyataan tersebut maka data dibawah tidak memunculkan gejala autokorelasi.

Tabel. 3 Uji Autokorelasi

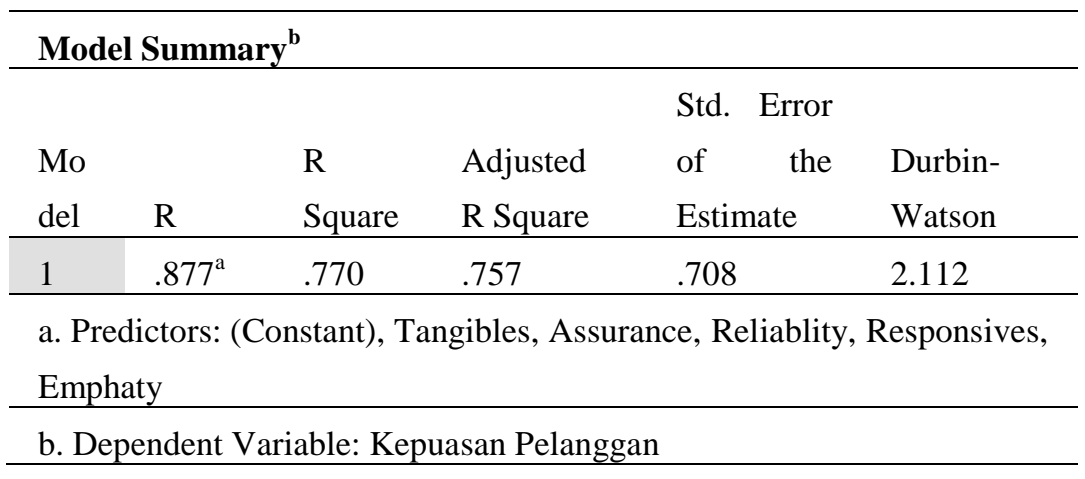

Sumber: Data Peneliti, 2020. 


\section{Uji Statistik T}

Uji $\mathrm{T}$ bertujuan untuk melihat pengaruh variabel independen tethadap variabel dependen dengan menganggap variabel lain bersifat konstan. Ghazali (2013) jika tabel Nilai Sig < 0,05 maka variabel independent $(X)$ secara parsial berpengaruh terhadap variabel dependent (Y). Dilihat dari uji $\mathrm{t}$ variable independent yang berpengaruh terhadap variable dependet hanya variabel Realibility (X1). Sedangkan variable resposives, assurance, emphaty, dan tangibles tidak berpengaruh terhadap variable kepuasan pelanggan.

\section{Tabel 4. Uji Statistik T}

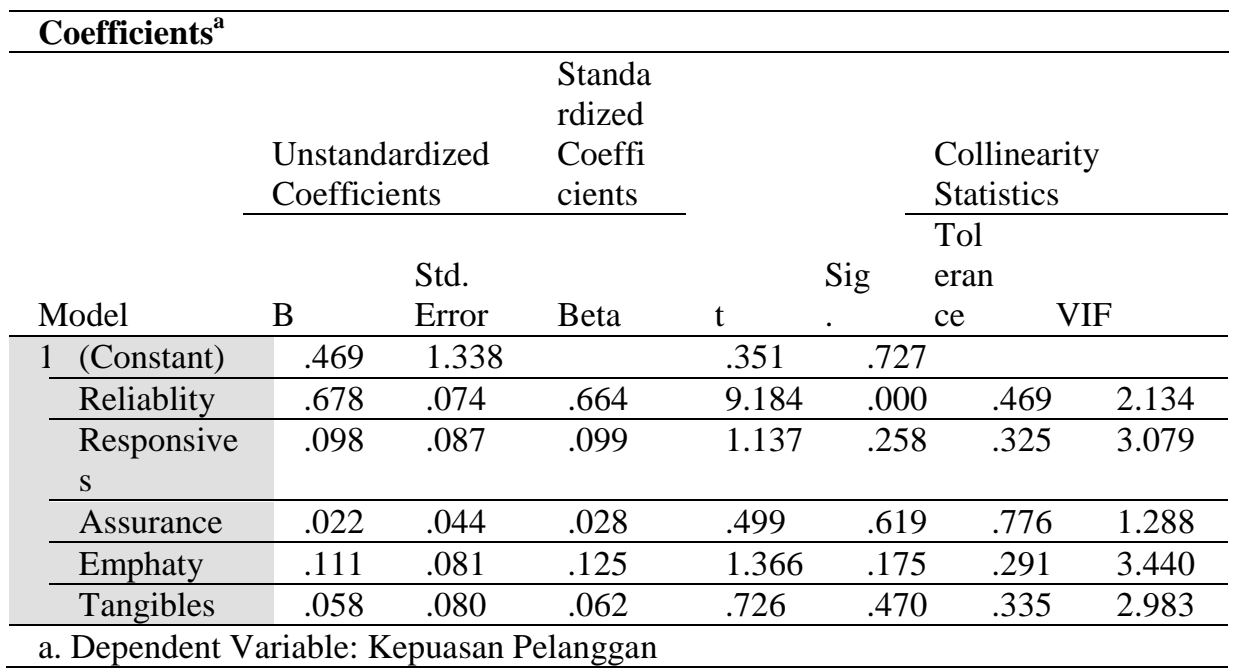

Sumber: Data Peneliti, 2020.

\section{Uji F}

Uji F digunakan untuk mengetahui pengarauh variabel independen terhadap variabel dependen, apakah variabel indenpeden mempunyai pengaruh secara simultan terhadap variabel dependen atau tidak (Ghazali, 2012). Tabel menunjukkan bahwa nilai sig. $<0,05$ yang berarti bahwa variabel independent $(\mathrm{x})$ secara simultan berpengaruh terhadap variabel dependen (Y). Nilai sig. adalah $0,000<0,05$ jadi variabel X1, X2, X3, $\mathrm{X} 4$, X5 secara bersama-sama mempunyai pengaruh terhadap variabel $\mathrm{Y}$. jadi dapat disimpulkan bahwa variable tangbiles, assurance, reliability, responsives, dan emphaty secara simultan berpengaruh terhadap kepuasan pelanggan. Dengan begitu seharusnya perusahaan dapat melakukan perbaikan serta restrukturisasi terhdap kualitas pelayanan. 
Hal ini bermanfaat untuk mendukung serta menciptakan keunggulan bersaing hingga menciptakan loyalitas konsumen.

Tabel 5. Uji F

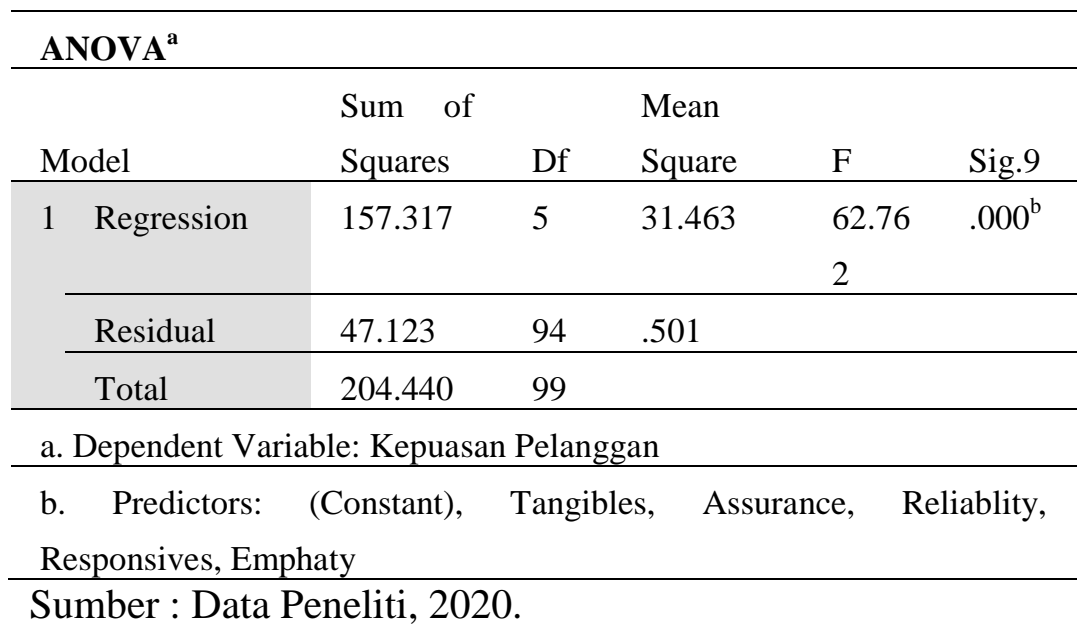

\section{Uji Koefisien Determinasi}

Koefisien determinasi $\left(\mathrm{R}^{2}\right)$ merupakan pengujian untuk mengukur besarnya kontribusi variabel independen terhadap variabel dependen. Besarnya koefisien 0 sampai 1, semakin mendekati 0 koefisien determinasi semakin kecil pengaruhnya terhadap variabel bebas. Sebaliknya mendekati 1 besarnya koefisien determinasi semakin besar pengaruhnya terhadap variabel bebas (Ghozali, 2013). Dari output dibawah, didapatkan nilai Adjusted R Square sebesar 0,757 yang artinya pengaruh variabel independen (X) terhadap variabel (Y) sebesar 75,7\%.

Tabel. 6 Uji Koefisien Determinasi

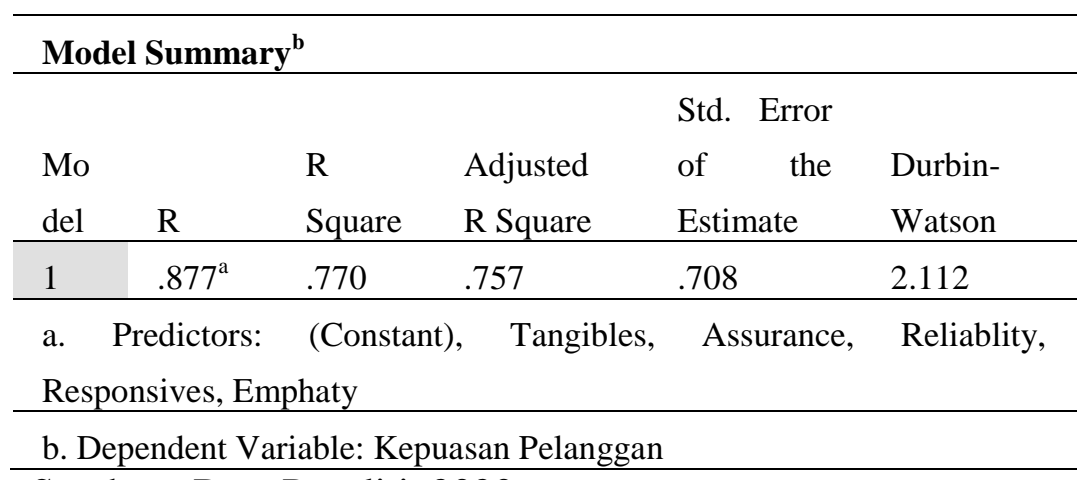

Sumber : Data Peneliti, 2020. 


\section{PENUTUP}

Dari hasil pengujian hipotesis uji t bahwa variabel tangibel, assurance, responsive, dan emphaty tidak berpengaruh signigikan terhadap kepuasan pelanggan bukan penerima upah. Reliability berpengaruh signifikan terhadap kepuasan pelanggan. Uji hipotesis (uji F) bahwa variabel Tangibels, Assurance, Reliability, Responsives, dan Emphaty secara simultan berpengaruh signifikan terhadap kepuasan pelanggan. Berdasarkan hasil analisis data dalam penelitian ini diperoleh kesimpulan bahwa variabel Tangibels, Assurance, Reliability, Responsives, dan Emphaty secara bersamasama berpengaruh terhadap Kepuasan Pelanggan. Maka dari itu perusahaan penyedia jasa harus selalu memperhatikan kualitas pelayanan yang baik sehingga dapat menciptakan kepuasan pelanggan.

Penelitian ini dapat digunakan perusahaan sebagai bahan pertimbangan dalam menciptakan proses pelayanan yang baik bagi konsumen sehingga perusahaan dapat memperoleh kepercayaan dari pelanggan serta menciptakan sikap loyal. Penelitian ini dapat digali lebih dalam sebagai bahan acuan dalam melakukan penelitian ke depannya.

\section{DAFTAR PUSTAKA}

Adam, Muhammad. 2015. Manajemen Pemasaran Jasa, Bandung: CV. Alfabeta.

Arie Vica Septiarani, N. W. (2013). Peningkatan Kualitas Pelayanan Nasabah Bpjs Ketenagakerjaan Dengan Metode Fuzzy-Servqual Dan Indeks Pgcv (Studi Kasus BPJS Ketenagakerjaan Cabang Malang) . 133-525.

Elu, Balthasar. (2005). Manajemen Penanganan Komplain Konsumen di Industri Jasa. Jurnal Ilmu Administrasi dan Organisasi, Bisnis\&Birokrasi, Vol. 13, No. 3 (September).

Fandy, Tjiptono. 2008. Strategi Pemasaran. Yogyakarta: CV. Andi Offset.

Ghozali, I. 2011. Aplikasi Analisis Multivariate dengan Program IBM SPSS 20 (6th ed.). Semarang: Universitas Diponegoro.

Kotler, P. 2000. Manajemen Pemasaran Indonesia, Alih Bahasa oleh Ancella Anitawati dan Hermawan, Edisi Pertama, Jakarta : Salemba Empat.

Kotler, Philip. 2002 . Manajemen Pemasaran Edisi Millenium. Jakarta: PT. Prehallindo. Kualitas Menurut Kamus Besar Indonesia, https://www.kbbi.kemendikbud.go.id/main/search/result?q=kualitas (diunduh tanggal 30 April 2020). 
Jurnal Kesejahteraan dan Pelayanan Sasial: e-ISSN: 2716-3857

Volume I, Nomar 2 (November, 2020) Hal. 148-160

Rohaeni, Heni. (2016). Model Gaya Kepemimpinan dan Motivasi Terhadap Kinerja Pegawai. Ecodemica, Vol.IV, No.1:2355-0295.

Sugiyono. 2015. Metode Penelitian dan Pengembangan, Penerbit Alfabeta Bandung. Yogyakarta.

Suharto, Abdul Majid. 2009. Customer Service dalam Bisnis Jasa Trasfortasi . Jakarta: PT Raja Grafindo Persada.

Tjiptono, F. 2011. Strategi Pemasaran, Edisi ke-2. Andi Offset. Yogyakarta.

Windarti, Ayu Oka. (2012). Pengaruh Kualitas Pelayanan Jasa Terhadap Kepuasan Nasabah Pada PT Bank Negara Indonesia Tbk. Kantor Cabang Utama Palembang. Jurnal Ekonomi dan Informasi Akuntansi. Vol.2 No.1 